\title{
Rheumatoid Arthritis of the Temporomandibular Joint; Comparison of Digital Panoramic Radiographs Taken Using the Joint Limitation Program [JLA View] and CT Scans
}

\author{
Antigone Delantoni \\ Department of Dentoalveolar Surgery, Implant Surgery and Radiology, Faculty of Dentistry, Aristotle University of Thessaloniki, \\ Thessaloniki, Greece. \\ Email: adelantoni@yahoo.com
}

Received February $29^{\text {th }}, 2012$; revised April $1^{\text {st }}, 2012$; accepted April $13^{\text {th }}, 2012$

\begin{abstract}
Objective: The aim of this study was to evaluate the efficacy of digital panoramic radiographs using the JLA view program in cases of rheumatoid arthritis and compare them to CT scans of the patients. Methods: 40 patients with known condition of RA and clinical symptoms in the TMJ were selected for the study. Radiological evaluation included a panoramic radiograph of the TMJs that was taken and a computer tomography of the joints. In the panoramic radiographs taken, isolation of the TMJs was done using the JLA view program, while in the CT scans of the patients, all scans were taken with closed mouth, with a distance of $0.5 \mathrm{~mm}$ per slice. The parameters examined were: 1) bony changes of the condyle; 2) the position of the condyle in the mandibular fossa; 3) the joint space; 4) bony changes of mandibular fossa. Results: There were no statistically significant differences found between the two observers or between the two joints of the same patient [right and left] on the panoramic radiographs. For the case of CT scans there were significant differences between the joint space of right and left joints, while in the ANOVA performed differences were found for the evaluation of the bony changes of the condyle. Conclusion: There were no significant differences between the two radiographic methods selected and therefore when a proper simple radiograph is taken and well evaluated, the conclusions drawn from it are well based and there is no need for further examinations.
\end{abstract}

Keywords: Rheumatoid Arthritis; Imaging; Temporomandibular Joint; Panoramic Radiography

\section{Introduction}

The temporomandibular joint [TMJ] is one the most frequently involved small joints of the skeleton in the case of inflammatory diseases, the most frequent of which is rheumatoid arthritis [1]. The radiographic involvement of the TMJ in inflammatory conditions has been studied and reported by many laboratories [1-5].

The lately introduced digital panoramic radiographs have not however been studied for the condition, though the efficacy of digital radiographs in other joints involved in the disease is not doubted anymore. The low radiation dose and the increased details of the radiographs plus the ability to manipulate the radiograph taken are the major advantages of digital radiographs.

Since the beginning of the description and classification of the TMJ syndrome by Costen in 1934 there has been no full clinical description of the condition until the 80's where Weinberg [3] first mentions the etiology and the need for a thorough and complete knowledge of the TMJ. Similar reports have been made by Laskin [1] where the author mentions the difficulty in classifying the condition since it has numerous causes but one clinical expression. In more recent studies the TMJ syndrome is always mentioned with the cause of the condition.

One can therefore state that though the temporomandibular joint is a frequently involved joint in rheumatoid arthritis, there has been little research on whether the conventional radiographic techniques are adequate for the joint's evaluation. In this paper an attempt to compare conventional imaging techniques to $\mathrm{CT}$ scans is made.

\section{Materials and Methods}

40 patients of known rheumatoid arthritis have been included in the study. The patients were of ages $19-57$ and had no other condition that could cause TMJ dysfunction 
(e.g. dentures, missing teeth, trismus, malocclusion etc.). They were selected among a number of 85 patients of rheumatoid arthritis and were carefully examined so that the disease would be active at the TMJ upon the examination (trigger points to muscles, clicking sounds etc.). Therefore the 40 patients selected were patients with RA that presented TMJ dysfunction syndrome. They were asked to take a digital panoramic radiograph of the TMJ (Joint Limitation Program) (Figure 1) and then a CT scan of the joint (Figure 2).

The panoramic radiographs were taken using the PM 2002 CC Proline orthopantomogram by Planmeka (PM 2002 CC Proline Panoramic X-Ray Unit, Planmeca Co. Helsinki, Finland) where the JLA program was applied (Joint limitation program). The CT scans were also performed the same way. All exams were performed with the patients mouth closed. Sections of 0,5 or $1 \mathrm{~mm}$ were selected to have homogeneity in all the exams and the viewing of the radiographs were performed. The radiographs taken were viewed by two expert Oral Surgeons and one Dentomaxillofacial Radiology expert who supervised the procedure prior to the analysis of the results.

The observers viewed the radiographs in random order and under identical conditions [dark room with ambient background light]. They were then asked to evaluate the condition of the joint based on points that could be

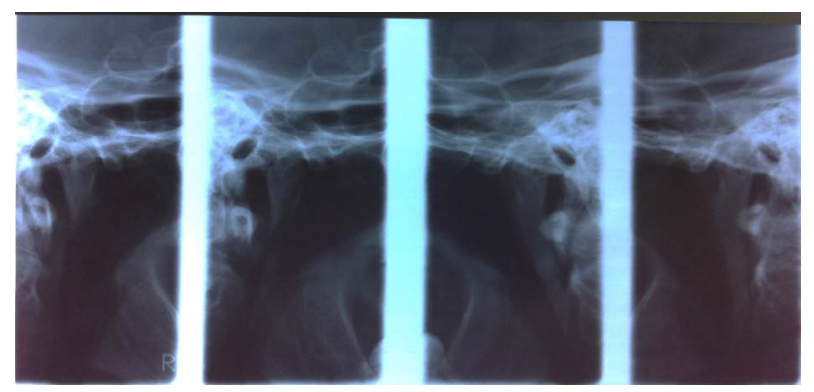

Figure 1. Panoramic radiograph using the Joint Limitation Program with open and closed mouth. They cystic lesions are prominent and easily identified.

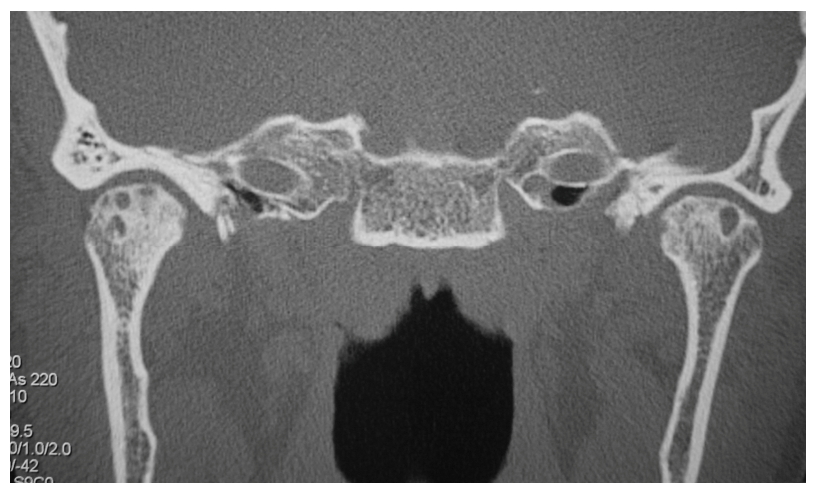

Figure 2. CT section of the same patient showing the cyst shaped erosions on the condylar head. viewed on the radiographs. Both right and left joint were viewed separately since the involvement of one joint does not necessarily mean involvement of the other joint.

The observers were asked to evaluate: 1) Bony changes of the condyle (flattening, erosion, osteophytes, sclerosis, resorption); 2) The position of the condyle in the mandibular fossa (anterior, concentric, posterior); 3) The joint space (increased, normal, reduced); 4) Bony changes of mandibular fossa [erosion, sclerosis, resorption, normal]. All images, both panoramic radiographs and the CT scans of the patients were examined for the above parameters by the observers.

\section{Results}

There was comparison made between the right and left joints of the patients and no statistically significant differences were found for the cases of panoramic radiographs ( $p$ value: 0.3836 ). For the case of CT scans there were significant differences between the joint space of right and left joints ( $p$ value: 0.1794), while in the ANOVA performed differences were found for the evaluation of the bony changes of the condyle ( $p$ value: 0.0153).

No statistical differences were found between right and left joints of the same patients for the case of panoramic radiographs while statistical significant differences were found between right and left joints for the case of the articular space and its size estimate ( $p$ value: 0.3026 ) which is partly expected since the articular space depends on the joints' elements and the two joints are completely independent.

Besides the initial descriptive statistics ANOVA was performed for each of the four areas of interest on the radiographs and the following results were obtained.

Statistical significant differences were measured between CT scans and panoramic radiographs for the 1st feature of the joint, meaning the condylar head and the lesions that appear on it. No statistical significant differences were found for the other three parts of the joint measured articular space, condylar head's position and temporal articular surface. The differences found for the condylar head between the two radiographic techniques measured are observed in Table 1.

Table 1. ANOVA table for A.

\begin{tabular}{ccc}
\hline & P value & Power \\
\hline Type & 0.0003 & 0.971 \\
Position & 0.4143 & 0.123 \\
Type + Position & 0.6829 & 0.069 \\
\hline
\end{tabular}


Due to the difference of the measurements for the condylar head evaluation there were differences found in the overall estimate of the joint as is observed in Table 2.

Due to the differences in the numbers given by the observers in order to evaluate the four different parts of the joint involved in RA Principal Component Analysis was performed. The PCA is a statistical technique that bears into account the gravity of each of the variables selected in the total result thus giving us more accurate results considering that each joint segment is of equal significance [as is assumed]. The results for the PCA was 0.882 (Table 3), proving that when each feature of the joint is equally valued there are no statistical significant differences between the two radiographic techniques selected.

Therefore the results obtained could be summarized to the following. There were no statistical significant differences between the two observers since a consensus decision was reached. There were differences between the two imaging modalities for the first of the four viewed features of the TMJ, the condylar head and its lesions. However the PCA which considers the importance of each independent variable, no statistical significant differences were measured between the two methods.

\section{Discussion}

The purpose of the current study was to subjectively study the radiographic findings in patient with TMJ syndrome that had a known history of rheumatoid arthritis. More specifically an attempt to correlate the radiographic findings according to the radiographic technique used and to measure the efficacy of conventional plain radiographs [panoramic] when compared to high specificity CT.

Table 2. ANOVA table for total.

\begin{tabular}{ccc}
\hline & P value & Power \\
\hline Type & 0.0351 & 0.556 \\
$\begin{array}{c}\text { Position } \\
\begin{array}{c}\text { Type + Posi- } \\
\text { tion }\end{array}\end{array}$ & 0.1028 & 0.354 \\
\hline
\end{tabular}

Table 3. Wilcoxon Signed Rank Test for condylar position between panoramic and $\mathrm{CT}$ scans.

\begin{tabular}{cc}
\hline \#0 Differences & 0 \\
\hline \#Ties & 1 \\
Z value & -0.148 \\
P value & 0.8825 \\
\hline
\end{tabular}

The first thorough radiographic analysis of the TMJ in cases of rheumatoid arthritis has been made by Worth in 1963 [4] though initial mention of the condition was in 1951 by Steinhardt [5] and Fiumicelli [6]. Since then there have been numerous studies involving the TMJ and rheumatoid arthritis. Tabeling and Dolwick 1985 [7] mention that $50 \%$ of the RA patients studied had TMJ problems. In 1987 a more thorough description of the clinical symptoms of the TMJ in patients with RA was made by Braunwald, Isselbacher $\kappa \alpha$ Petersdorf [8] where the radiological symptoms are well described.

In the present study a clinical examination protocol used by the Dental Faculty [altered Helkimo] was used to determine the patients to be included in the study. Patients with a known RA history showed a higher TMJ syndrome condition (40 out of 85) than the patients not included in the study ( 45 of the initial 85 ). Similar results have been presented in numerous studies [9-16].

In previous studies the frequency of TMJ involvement in RA varies from $2 \%$ to $98 \%$ [17]. In the majority of reports though $40 \%$ to $50 \%$ of all RA patients presents some clinical involvement of the TMJ [18-20]. This result is in agreement with the results from the present study since from the initial number of patients 40 fulfilled all the criteria to be included in the study.

For the radiographic implications of the condition most authors agree to a percentage of about $60 \%$ involvement for CT scans in the case of known RA of the patients ranging from $50 \%$ to $80 \%[7,21]$. There is agreement that the radiographic findings of the patients are not as visible in the initial stages of the condition while the primary lesions are the erosions the anterior and inner condylar surface. The initial lesions are not as visible in panoramic radiographs $[22,23]$. However in the present study in the cases of involvement of the TMJ for lesions that are not extended [erosions and osteophytes, there were no significant statistical differences between the two methods This is in agreement with the number of authors that claim that the Joint Limitation Program [JLA view] is more useful in the patients classification and as markers for the joints inflammatory condition [24,25]. What should be noted here is that in the present study a large number of patients with active RA of the TMJ were not included in the study for other reasons such as occlusal problems, trismus and other conditions. If all active RA patients were included, the percentile of patients having radiographic findings could be significantly higher.

Regarding the comparison of the two different techniques, though there were differences between the isolated findings of both techniques [condylar head] there were no statistical significant differences overall in the joints. The reason for this is that the condylar head im- 
aging is significantly different in imaging between the two methods [panoramic and CT] due to the large number of anatomical elements that superimpose it in panoramic radiographs $[26,27]$. Also CT scans are known to have a larger specificity in small size lesions [28-31]. However it is of great value that overall there were no differences between the two techniques which could partly prove the importance of a detailed initial radiographic examination that could not mean large radiation doses as is the case of CT.

Conclusively we can say that there is increased involvement of the TMJ in the patients with RA. The involvement is visible in simple radiographs such as digital panoramic radiographs if they are properly taken though CT scans do tend to have a higher specificity and detail in the case of initial lesions. In the present study there were no significant differences found between the two radiographic methods selected for both joints, and therefore when a proper simple radiograph is taken and well evaluated, the conclusions drawn from it are well based and there is no need for further examinations.

\section{REFERENCES}

[1] D. M. Laskin, "Diagnosis of Pathology of the Temporomandibular Joint, Clinical and Imaging Perspectives," $R a$ diologic Clinics of North America, Vol. 31, No. 1, 1993, pp. 135-147.

[2] H. H. Yilmaz, D. Yildirim, Y. Ugan, S. E. Tunc, A. Yesildag, H. Orhan and C. Akdag, "Clinical and Magnetic Resonance Imaging Findings of the Temporomandibular Joint and Masticatory Muscles in Patients with Rheumatoid Arthritis," Rheumatology International, Vol. 32, No. 5, 2011, pp. 1171-1178.

[3] L. A. Weinberg, "The Etiology, Diagnosis, and Treatment of TMJ Dysfunction-Pain Syndrome. Part I: Etiology," Journal of Prosthetic Dentistry, Vol. 42, No. 6, 1979, pp. 654-664. doi:10.1016/0022-3913(79)90197-5

[4] H. M. Worth, "Principles and Practice of Oral Radiographic Interpretation," Year Book Medical Publishers, Chicago, 1963.

[5] G. Steinhardt, "Rheumatoid Arthritis of the Temporomaxillary Joint," Zeitschrift fur Laryngologie, Rhinologie, Otologie und Ihre Grenzgebiete, Vol. 30, No. 11, 1951, pp. 475-485.

[6] A. Fiumicelli, "Involvement of the Temporo-Mandibular Joint in Rheumatoid Arthritis," Nova Acta Stomatol, Vol. 3, No. 1, 1951, pp. 1-10.

[7] H. J. Tabeling and M. F. Dolwick, "Rheumatoid Arthritis: Diagnosis and Treatment," Florida Dental Journal, Vol. 56, No. 1, 1985, pp. 16-18.

[8] E. Braunwald and R. G. Petersdorf, "Harrison's Principles of Internal Medicine," McGraw-Hill, New York, 1987.

[9] B. Wenneberg, L. Hollender and S. Kopp, "Radiographic
Changes in the Temporomandibular Joint in Ankylosing Spondylitis," Dentomaxillofacial Radiology, Vol. 12, No. 1, 1983, pp. 25-30.

[10] B. Wenneberg, S. Kopp and L. Hollender, "The Temporomandibular Joint in Ankylosing Spondylitis. Correlations between Subjective, Clinical, and Radiographic Features in the Stomatognathic System and Effects of Treatment," Acta Odontologica Scandinavica, Vol. 42, No. 3, 1984, pp. 165-173. doi:10.3109/00016358408993868

[11] P. L. Westesson, "Temporomandibular Joint and Dental Imaging," Neuroimaging Clinics of North America, Vol. 6, No. 2,1996, pp. 333-355.

[12] K. Marton, "Oral Symptoms of Immunologic Disorders. Part I. Systemic Autoimmune Diseases," Fogorvosi Szemle, Vol. 96, No. 1, 2003, pp. 9-15.

[13] A. G. Pullinger, D. A. Seligman and W. K. Solberg, "Temporomandibular Disorders. Part I: Functional Status, Dentomorphologic Features, and Sex Differences in a Nonpatient Population," Journal of Prosthetic Dentistry, Vol. 59, No. 2, 1988, pp. 228-235. doi:10.1016/0022-3913(88)90019-4

[14] A. G. Pullinger, D. A. Seligman and W. K. Solberg, "Temporomandibular Disorders. Part II: Occlusal Factors Associated with Temporomandibular Joint Tenderness and Dysfunction," Journal of Prosthetic Dentistry, Vol. 59, No. 3, 1988, pp. 363-367. doi:10.1016/0022-3913(88)90191-6

[15] D. E. Ryan, "Temporomandibular Disorders," Current Opinion in Rheumatology, Vol. 5, No. 2, 1993, pp. 209218. doi:10.1097/00002281-199305020-00014

[16] P. N. Scutellari, C. Orzincolo and S. Ceruti, "The Temporo-Mandibular Joint in Pathologic Conditions: Rheumatoid Arthritis and Seronegative Spondyloarthritis," Radiologia Medica, Vol. 86, No. 4, 1993, pp. 456-466.

[17] M. Kononen, B. Wenneberg and A. Kallenberg, "Craniomandibular Disorders in Rheumatoid Arthritis, Psoriatic Arthritis, and Ankylosing Spondylitis: A Clinical Study," Acta Odontologica Scandinavica, Vol. 50, No. 5, 1992, pp. 281-287. doi:10.3109/00016359209012774

[18] I. M. Chalmers and G. S. Blair, "Rheumatoid Arthritis of the Temporomandibular Joint. A Clinical and Radiological Study Using Circular Tomography," Quarterly Journal of Medicine, Vol. 42, No. 166, 1973, pp. 369-386.

[19] J. E. Chenitz, "Rheumatoid Arthritis and Its Implications in Temporomandibular Disorders," Cranio, Vol. 10, No. 1, 1992, pp. 59-69.

[20] T. A. Larheim, H. J. Smith and F. Aspestrand, "Rheumatic Disease of the Temporomandibular Joint: MR Imaging and Tomographic Manifestations," Radiology, Vol. 175, No. 2, 1990, pp. 527-531.

[21] N. Bayar, S. A. Kara, I. Keles, M. C. Koc, D. Altinok and S. Orkun, "Temporomandibular Joint Involvement in Rheumatoid Arthritis: A Radiological and Clinical Study," Cranio, Vol. 20, No. 2, 2002, pp. 105-110.

[22] E. T. Koh, A. U. Yap, C. K. Koh, T. S. Chee, S. P. Chan and I. C. Boudville, "Temporomandibular Disorders in Rheumatoid Arthritis," Journal of Rheumatology, Vol. 26, 
No. 9, 1999, pp. 1918-1922.

[23] L. Z. Arvidsson, B. Flatø and T. A. Larheim, "Radiographic TMJ Abnormalities in Patients with Juvenile Idiopathic Arthritis Followed for 27 Years," Oral Surgery, Oral Medicine, Oral Pathology, Oral Radiology and Endodontics, Vol. 108, No. 1, 2009, pp. 114-123.

[24] L. M. Helenius, D. Hallikainen, I. Helenius, J. H. Meurman, M. Kononen, M. Leirisalo-Repo and C. Lindqvist, "Clinical and Radiographic Findings of the Temporomandibular Joint in Patients with Various Rheumatic Diseases. A Case-Control Study," Oral Surgery, Oral Medicine, Oral Pathology, Oral Radiology, and Endodontics, Vol. 99, No. 4, 2005, pp. 455-463. doi:10.1016/i.tripleo.2004.06.079

[25] P. L. Westesson, "Temporomandibular Joint and Dental Imaging," Neuroimaging Clinics of North America, Vol. 6, No. 2, 1996, pp. 333-355.

[26] J. V. Manzione, R. W. Katzberg and T. J. Manzione, "Internal Derangements of the Temporomandibular Joint. II. Diagnosis by Arthrography and Computed Tomography," International Journal of Periodontics \& Restorative Den- tistry, Vol. 4, No. 4, 1984, pp. 16-27.

[27] T. A. Larheim, "Comparative Imaging of the Temporomandibular Joint," Current Opinion in Dentistry, Vol. 2, 1992, pp. 163-169.

[28] T. A. Larheim, "Comparison between Three Radiographic Techniques for Examination of the Temporomandibular Joints in Juvenile Rheumatoid Arthritis," Acta Radiologica Diagnosis, Vol. 22, No. 2, 1981, pp. 195-201.

[29] T. A. Larheim, "Imaging of the Temporomandibular Joint in Rheumatic Disease," Cranio Clinics International, Vol. 1, No. 1, 1991, pp. 133-153.

[30] T. A. Larheim, T. Bjornland, H. J. Smith, F. Aspestrand and A. Kolbenstvedt, "Imaging Temporomandibular Joint Abnormalities in Patients with Rheumatic Disease. Comparison with Surgical Observations," Oral Surgery, Oral Medicine, Oral Pathology, Vol. 73, No. 4, 1992, pp. 494501. doi:10.1016/0030-4220(92)90333-L

[31] T. A. Larheim, H. J. Smith and F. Aspestrand, "Rheumatic Disease of the Temporomandibular Joint: MR Imaging and Tomographic Manifestations," Radiology, Vol. 175 , No. 2, 1990, pp. 527-531. 